\title{
Interpretation of 9 Selected Visual Works of Contemporary Young Talent from the Context of the National Cultural Policy Core
}

\section{Interpretasi 9 Karya Seni Visual Terpilih Bakat Muda Sezaman Dari Konteks Teras Dasar Kebudayaan Kebangsaan}

\author{
Firdaus Naif Omran Zailuddin ${ }^{1}$, Muhammad Abdullah ${ }^{2}$, Hawari Berahim ${ }^{3}$ \& Azharudin Mappon ${ }^{4}$ \\ ${ }^{1}$ Fakulti Teknologi Kreatif \& Warisan \\ ${ }^{2}$ Fakulti Seni Lukis \& Reka, Universiti Teknologi MARA (Perak) \\ ${ }^{3,4}$ Universiti Malaysia Kelantan \\ Authors' email: firdaus.oz@umk.edu.my ${ }^{1}, \underline{\text { muham725@perak.uitm.edu.my }}{ }^{2}$ \\ hawari@umk.edu.my ${ }^{3}$, azharuddin@umk.edu.my ${ }^{4}$
}

Published: 7 September 2018

\begin{abstract}
Contemporary Young Talent (CYT) is a visual arts competition organized by the National Visual Arts Gallery (NVAG) which is the most prestigious in Malaysia. Its 40 years of organization have successfully produced many renowned artists who are now pioneers in the Malaysian and regional visual arts arena. In line with the strength of CYT as a reflection of the future of Malaysian visual arts and the role of art as a cultural vehicle, the objective of the study is to analyze and further dismantle the latest visual art works of Malaysian artists from the perspective of national culture through the CYT platform from 2000 to 2013. This study aims to clearly understand the visual elements and features that are the cultural identity in the latest Malaysian visual arts. This objective was achieved through observation and reading of CYT catalog books published by NVAG, scholarly books, journals, and relevant previous studies as well as interviews on three artists and academics who won the CYT competition. This study uses a qualitative approach, guided by the 4 components of the theory of art criticism Feldman E.B. (1994) namely description, analysis, interpretation and evaluation. 9 works will be analyzed from the aspects of 'form' and 'meaning'. The results of the work analysis will be compared with national cultural elements (data triangulation) and then justify and classify CYT visual art works based on the 3 cores of the National Cultural Policy, namely, the culture of the region's indigenous peoples, other appropriate cultures and Islamic culture through descriptive text.). This study is important to create awareness, deeper appreciation and provide knowledge to art admirers in understanding the meaning and approach and content in the latest visual artwork. The results of the study through descriptive texts explain the existence of national cultural elements and their relationship in selected contemporary works of CYT (2000-2013).
\end{abstract}

Keywords: Interpretation, Contemporary Young Talent, National Cultural Policy

\section{ABSTRAK}

Bakat Muda Sezaman (BMS) merupakan pertandingan seni visual anjuran Balai Seni Visual Negara (BSVN) yang paling berprestij di Malaysia. 40 tahun penganjurannya telah berjaya melahirkan ramai artis ternama yang kini menjadi pelopor dalam arena seni visual Malaysia dan serantau. Sesuai dengan kekuatan BMS sebagai cerminan masa depan seni visual Malaysia dan peranan seni sebagai wadah budaya bangsa, objektif kajian bertujuan untuk menganalisis dan seterusnya merungkai karya-karya seni visual terkini artis Malaysia dari perspektif budaya kebangsaaan melalui platform BMS dari tahun 2000 hingga 2013. Melalui objektif ini, kajian berhasrat untuk memahami dengan jelas elemen dan ciri-ciri visual yang menjadi identiti budaya di dalam seni visual Malaysia terkini. Objektif ini dicapai menerusi pemerhatian dan pembacaan buku-buku katalog BMS keluaran BSVN, buku-buku ilmiah, 
jurnal, dan kajian-kajian terdahulu yang relevan selain temu bual ke atas tiga artis dan ahli akademik yang memenangi pertandingan BMS. Kajian ini menggunakan pendekatan kualitatif, berpandukan 4 komponen teori kritikan seni Feldman E.B. (1994) iaitu penerangan, analisis, interpretasi dan penilaian. 9 karya akan dianalisis dari aspek 'bentuk' dan 'makna'. Keputusan analisis karya akan dibandingkan dengan elemen budaya kebangsaan (triangulasi data) dan seterusnya menjustifikasi dan mengkelaskan karya-karya seni visual BMS berdasarkan 3 teras Dasar Kebudayaan Kebangsaan iaitu, budaya rakyat asal rantau, budaya lain yang sesuai dan budaya Islam melalui teks deskriptif (descriptive text). Kajian ini penting untuk mewujudkan kesedaran, penghayatan yang lebih mendalam dan memberikan pengetahuan kepada penghayat seni dalam memahami makna dan pendekatan dan isi di dalam karya seni visual terkini. Hasil kajian melalui teks deskriptif menjelaskan keberadaan elemen budaya kebangsaan dan hubungannya di dalam karya-karya kontemporari terpilih BMS (2000-2013). Key Words: Interperetasi, Bakat Muda Sezaman, Dasar Kebudayaan Kebangsaan

eISSN: 2550-214X (C) 2018. The Authors. Published for Idealogy Journal of Arts and Social Science by UiTM Press. This is an Open Access article distributed under the terms of the Creative Commons Attribution-NonCommercial-NoDerivatives License (http://creativecommons.org/licenses/by-nc-nd/4.0/), which permits non-commercial re-use, distribution, and reproduction in any medium, provided the original work is properly cited, and is not altered, transformed, or built upon in any way.

\section{PENGENALAN}

Seiring dengan era globalisasi, karya kontemporari ataupun sezaman telah mendapat tempat di dalam landskap seni visual Malaysia. Karya kesenian ini diwarnai dengan kepelbagaian isu dan tema dengan tujuan memberi kefahaman mengenai dunia seni kontemporari dengan berlatar belakangkan masyarakat Malaysia. Beverly Young (2000) di dalam artikel bertajuk "Art in Malaysia - Starting Thougths" telah membandingkan landskap seni Malaysia dan arena seni antarabangsa. Berdasarkan pengamatannya, seni visual Malaysia dilihat masih lagi ketinggalan berbanding negara-negara lain yang telah lama bertapak arena seni antarabangsa. Melihat kembali kepada sejarah seni Malaysia, tidak dapat dinafikan kita masih lagi 'muda' di dalam perjalanan seni yang pendek. Memperincikan keadaan seni Malaysia:

"All the players in the story - the pioneers, the "modernists", the contemporaries of the art world, are still alive or at least fresh in our memories. Traditional art forms remain in practice alongside the avant- garde, even while feeding into contemporary art. The people, intrigues and debates which have spiced up our art history are still recent gossip. There is ample material to be built on, and a future ahead." Beverly Young (2000 : 1)

Namun begitu, seni malaysia telah mengalami perkembangan yang cukup signifikan dari masa ke masa terutamanya dengan tertubuhnya balai seni lukis negara (BSLN) pada tahun 1958. Era 1960an menyaksikan tertubuhnya maktab perguruan ilmu khas yang membuka peluang kepada guru-guru berpengalaman untuk melanjutkan pengajian di dalam bidang seni di institusi luar negara. Usaha kerajaan ini telah menghasilkan sekumpulan guru seni yang lebih mahir dan berpengetahuan luas seperti syed ahmad jamal, yeoh jin leng, anthony lau, lee joo fong, ismail zain dan lain-lain. Seterusnya, pendidikan seni telah diperkenalkan secara formal melalui penubuhan institut teknologi mara (ITM) pada tahun 1967, kini dikenali sebagai universiti teknologi mara (UITM). Antara pelukis-pelukis terkenal yang lahir daripada institusi ini adalah ruzaika omar basree, amron omar, ponirin amin, jailani abu hassan dan ramai lagi.

Tahun 1971 memperlihatkan anjakan yang amat ketara di dalam pergerakan seni visual Malaysia dengan kelahiran Kongres Kebudayaan Kebangsaan yang seterusnya mewujudkan Dasar Kebudayaan Kebangsaan (DKK). Kebudayaan Malaysia dikenali dengan ciri-ciri unik melalui kepelbagaian yang ada pada masyarakatnya yang majmuk. Oleh kerana Malaysia merupakan sebuah negara berbilang kaum yang terdiri daripada tiga kaum besar iaitu Melayu, Cina dan India, setiap etnik mempunyai budaya dan tradisi yang tersendiri. Bagaimanapun, keindahan kepelbagaian ini tergugat dengan peristiwa rusuhan kaum pada 13 Mei 1969 sehinggalah kerajaan pada masa itu bertindak memperkenalkan Dasar Kebudayaan Kebangsaan dengan matlamat utama membina perpaduan di dalam kepelbagaian. 
Pengaruh Dasar Kebudayaan Kebangsaan dapat dilihat dengan jelas pada sekitar awal tahun 1980an apabila pelbagai karya bercirikan Islam dan kebudayaan Melayu dapat dilihat di dalam karya-karya dan pemeran-pameran seni visual. Menurut Samiati: Dzulhilmi: Rahman (2013), selain pengaruh Dasar Kebudayaan, perkara ini juga berlaku seiring dengan revolusi Iran yang membawa "world global Islamic revival”. Mulyadi Mahmood (2012) turut menyatakan perkara yang sama

berkenaan impak kongres dan revolusi Iran terhadap arena seni Malaysia:

"Di samping kesedaran dan gerak rasa diri pelukis, terdapat faktor-faktor kontekstrual yang mendorong tercetusnya karya dan pameran bernafaskan Islam, antaranya kesan pembentukan Dasar Kebudayaan Kebangsaan (1971), Seminar Akar-akar Pribumi (1979) dan kebangkitan serta kecenderungan global terhadap Islam pada dekad 1980-an"

Mulyadi Mahmood (2012: 18)

Intipati daripada Dasar Kebudayaan Kebangsaan (DKK) juga telah diangkat oleh Syed Ahmad Jamal yang pada ketika itu merupakan Pengarah di Muzium Seni Asia, Universiti Malaya. Beliau telah mengadakan pameran "Rupa dan Jiwa" yang merupakan sebuah pameran berdasarkan estetika budaya dan jiwa Islam. Pameran ini juga merupakan cetusan daripada Seminar Akar-Akar Kesenian Peribumi dan Perkembangan Kini anjuran Kajian Senilukis dan Senireka Institut Teknologi MARA pada Disember 1979. Faizal Sidek (2010) menyatakan berlaku penampakkan pengaruh daripada pameran ini di dalam perkembangan pertandingan Bakat Muda Sezaman (BMS) tahun 1980an. Menurutnya, terjadi revivalisme atau memunculkan semula kesenian tradisi dan peribumi, mitos dan lagenda seperti kraf, pantun, yang diberi nafas baru di dalam konteks sezaman yang segar.

Antara karya-karya Bakat Muda Sezaman (BMS) yang mengandungi nilai-nilai semangat dan falsafah budaya adalah karya Mohamed Nasir Baharuddin "Dari Satu Keujudan" (BMS 1984), karya Jalaini Abu Hassan "Catan Orang Kampung IV" (BMS 1985), karya Mohamed Akif Emir, "Home Sweet Home" (BMS 1987), karya Tumian Tasman "Kebudayaan XVI" (BMS 1989) dan lain-lain lagi. Namun begitu, kajian-kajian berkenaan implikasi DKK ke atas praktis seni hanya tertumpu pada era 80an dan 90an sahaja.

Tiada lagi kajian yang cuba menghubungkan dan seterusnya menilai sejauh mana keberkesanan dasar ini ke atas karya-karya seni visual abad ini.

Oleh itu, adalah menjadi satu tuntutan untuk dijadikan kajian terhadap interpretasi karya-karya BMS yang terkini dari sudut budaya kebangsaan. Hal ini kerana, budaya merupakan sesuatu yang dinamik dan berubah-ubah. Dalam mengkaji dan menilai impak pelaksanaan DKK, ianya tidak harus berkisarkan kesan jangka pendek semata-mata akan tetapi perlu dipanjangkan untuk dilihat dalam jangka masa yang panjang. BMS merupakan anungerah seni visual terpenting di Malaysia selain boleh dilihat sebagai cerminan masa depan seni visual Negara. Maka, amat penting bagi karya-karya ini diangkat dan difahami peranannya kepada masyarakat.

\section{PENYATAAN MASALAH}

Berdasarkan kajian semasa dan lampau yang berkaitan dengan perkembangan seni kontemporari/sezaman di Malaysia, terdapat banyak kekurangan dan kelompongan yang perlu diisi oleh pengkaji kini. Azian Tahir (2008) menyatakan dengan jelas berkenaan ketiadaan maklumat terperinci dalam aspek bentuk dan makna karya- karya yang memenangi BMS. Hal ini memperlihatkan kurangnya apresiasi terhadap karya-karya BMS yang sebenarnya amat penting di dalam perkembangan seni visual Malaysia dan seni rumpun (SERUM).

Kajian yang hampir berkenaan impak atau implikasi pelaksanaan dasar kebudayaan adalah penulisan Azian Tahir dan Rosiah Md Noor (2009) bertajuk "Kesedaran Pelukis Moden Malaysia dalam Seni Islam Berlandaskan Dasar Seni Kebangsaan". Penulisan ini membicarakan perihal karya-karya 
seni visual yang menyentuh elemen ketiga DKK. DKK di dalam penulisan ini dirujuk sebagai Dasar Seni Kebangsaan. Akan tetapi, penulisan hanya menyentuh tentang konteks Islam sahaja selain karyakarya yang dianalisis tertumpu kepada karya-karya lama.

Azian Tahir dan Rosiah Md Noor (2010) sekali lagi menghasilkan makalah berkenaan DKK bertajuk "An Analysis Study on Printmaking Artwork with the National Cultural Identity Theme in Malaysia". Penulisan ini menjelaskan secara deskriptif elemen-elemen budaya kebangsaan yang terdapat di dalam karya-karya yang terpilih. Namun begitu, penulisan ini hanya mengulas berkenaan pengaruh Dasar Kebudayaan bagi karya seni visual yang menggunakan medium cetakan sahaja.

Penulisan tesis Ahmadrashidi Hasan (2010) membincangkan mengenai lukisan Islam kontemporari Malaysia bermula dari 1980an hingga tahun 2000. Penyelidikan memperincikan bentuk dan simbol Islam, bahan-bahan yang digunakan serta minat yang terlahir dalam memanifestasikan karya seni berbentuk keagamaan. Penyelidikan beliau mendapati kesenian Islam memainkan peranan yang utama selain signifikan terhadap pembangunan seni moden Malaysia terutamanya pada era 90an. Penulisan tidak menjelaskan karya dari sudut formalistik selain penyelidikan tidak membincangkan karya-karya terkini.

Kajian oleh Mohammad Noh, Ahmadrashidi Hasan, Hamdzun Haron dan Ab. Latif Samian (2014) pula mengkaji mengenai teknik dan media yang digunakan di dalam seni bergambar Malaysia. Karyakarya ini dianalisis menggunakan ekspresi simbol Melayu. Kajian ini bertujuan menyiasat teknik terbaik dan keberkesanannya terhadap penciptaan kesan visual dalam seni bergambar terutamanya menggunakan simbol ekspresi melayu. Hasil kajian mendapati kebanyakkan artis menggunakan media campuran berbanding media konvensional seperti cat minyak, di dalam menghasilkan simbol Melayu. Namun, penyelidikan ini tidak pula menyentuh tentang jenis simbol Melayu yang sentiasa digunakan oleh artis di Malaysia di dalam karya-karya mereka.

Sarena Abdullah (2011) dalam kajian bertajuk "Thematic Approach in Malaysia Art Since 1990's" telah melihat pendekatan yang digunakan oleh artis-artis Malaysia pada ketika itu. Penulis telah membincangkan kesan daripada pendekatan bertema yang digunakan untuk subjek, tema, dan media di kalangan artis-artis Melayu. Kajian menyentuh berkenaan pendekatan bertema di dalam berkarya yang dilihat membawa kepentingan dan isu golongan kelas pertengahan Malaysia di mana artis itu berasal. Penulis tidak menerangkan aspek nilai kebudayaan Melayu, bentuk dan kaitannya dengan dasar yang diperkenalkan.

Tidak dapat dinafikan, DKK secara tidak langsung telah menjadi asas dan garis panduan kepada artis Malaysia dalam mencari arah tuju pencarian identity kebangsaan. Dasar ini telah mencorakkan perjalanan seni visual Malaysia. Tiga teras utama kebudayaan kebangsaan telah diperkenalkan pada Kongres Kebudayaan Kebangsaan. Teras pertama adalah kebudayaan kebangsaan Malaysia hendaklah berteraskan kepada kebudayaan rakyat asal rantau ini. Kedua, unsur-unsur kebudayaan lain yang sesuai dan wajar boleh diterima menjadi unsur-unsur kebudayaan kebangsaan. Terakhir sekali, Islam perlu menjadi unsur penting dalam pembentukan kebudayaan kebangsaan. Kesannya, pasca 1970 memperlihatkan gaya dan tema yang berkisarkan isu nasional, identiti sosial dan budaya di dalam karya artis-artis Malaysia (Mulyadi Mahamood, 2001).

Namun begitu, persoalan berkenaan kesan DKK tidak dibincangkan dalam konteks karya-karya seni visual kontemporari terutamanya pada pasca 2000. Persoalannya, adakah kesan DKK hanya berlaku pada era 80an dan 90an sahaja seterusnya usaha dan keinginan untuk mengangkat budaya kebangsaan ini terkubur begitu sahaja. Maka, segala segala persoalan yang timbul tidak akan terjawab dan masih lagi menjadi persoalan selagi mana kajian mengenainya tidak dijalankan.

Berdasarkan pernyataan masalah yang dikemukakan, satu kajian berkenaan interpretasi karya-karya terkini BMS dari tahun 2000 hingga 2013 akan dijalankan dari konteks kebudayaan kebangsaan. Kajian akan dijalankan menggunakan rangka kerja teori Kritikan Seni yang diperkenalkan Feldman E.B. (1994) menerusi bukunya "Practical Art Criticism". 
Teori kritikan seni ini telah dipilih kerana mempunyai kerangka yang jelas dan sistematik dalam membantu proses menganalisis karya yang hendak dilakukan. Bagi melahirkan kajian yang lebih berkesan, kajian juga merujuk kepada artis terlibat yang berlatarbelakangkan bidang akademik bagi memahami dengan jelas aspek bentuk dan makna di dalam karya seni visual yang dihasilan.

\section{OBJEKTIF KAJIAN}

Berdasarkan daripada permasalahan kajian telah dikemukakan, (2) objektif kajian telah dirumuskan:

I. Menganalisis dan menginterpretasi aspek 'bentuk' dan 'makna' 9 Karya terpilih daripada artis muda Malaysia melalui platform BMS dari tahun 2000 hingga 2013.

II. Menilai dan memahami isi kandungan karya yang dihasilkan artis BMS (2000-2013) yang mempunyai hubungan dengan elemen-elemen budaya kebangsaan.

\section{SKOP KAJIAN}

Skop bagi penyelidikan ini adalah untuk mengkaji isi kandungan karya kontemporari artis muda Malaysia melalui platform BMS dari tahun 2000 hingga 2013 berdasarkan tiga unsur kebudayaan kebangsaan dan juga beberapa perkara yang berkaitan dengan perbincangan. Kajian dihadkan kepada kajian unsur kebudayaan kebangsaan yang terdapat di dalam karya sahaja bagi menentukan skop dan sempadan kajian.

Hal ini bagi memastikan keterbatasan kajian dapat dikawal. Selain itu, kajian juga hanya tertumpu kepada karya-karya penerima anugerah/ pemenang BMS dari tahun 2000 hingga terkini 2013 sahaja memandangkan karya-karya ini diperakukan kualiti dan kekuatannya. Selain itu, karya juga dipilih berdasarkan kandungan karya yang bercirikan kebudayaan kebangsaan sahaja. BMS merupakan satusatunya pertandingan yang berprestij bagi penggiat seni lukis di Malaysia dan diadakan secara konsisten. BMS juga mempunyai peranan besar dalam mengukur perkembangan seni lukis negara dari konteks sezaman, mendefinasikan masyarakat, etika budaya (cultural ethos) dan isu-isu semasa. Oleh itu, BMS dilihat relevan sebagai pengukuran cerminan budaya melalui disiplin seni visual di Malaysia.

\section{KEPENTINGAN KAJIAN}

Hasil daripada kajian ini akan dapat memberikan gambaran yang jelas dalam menginterpretasi sesebuah karya yang menjawab dan memaparkan unsur-unsur kebudayaan kebangsaan Malaysia berdasarkan "Dasar Kebudayaan Kebangsaan 1971".

Hasil kajian ini juga diharap dapat memberikan pendedahan dan kefahaman secara langsung dan tidak langsung kepada penggiat seni visual kontemporari dan juga masyarakat tempatan mengenai kebudayaan kebangsaan Malaysia.

Hal ini kerana dalam era globalisasi yang berubah begitu pantas, di samping keunikan Malaysia sebagai negara "multiracial" dan "multiculture", kefahaman yang jelas berkenaan kebudayaan bangsa adalah amat penting dan kritikal bagi meneruskan kelangsungan perpaduan di kalangan masyarakat. Pemahaman yang jelas berkenaan unsur kebudayaan kebangsaan akan dapat memberi nilai tambah dalam menghasilkan sesebuah karya yang matang dan intelektual dalam konteks wadah bangsa.

Sudah tentu kita ingin melihat penggiat seni, melalui karya mereka memainkan peranan yang signifikan dalam membina dan memperkukuhkan identiti budaya bangsa bukan sahaja di dalam negara, bahkan di arena antarabangsa. Kajian juga ini diharapkan menjadi satu dokumentasi terhadap perkembangan seni visual sezaman tempatan secara amnya dan memberi makna kepada aspek identiti 
kebudayaan bangsa khususnya.

\section{KERANGKA TEORITIKAL}

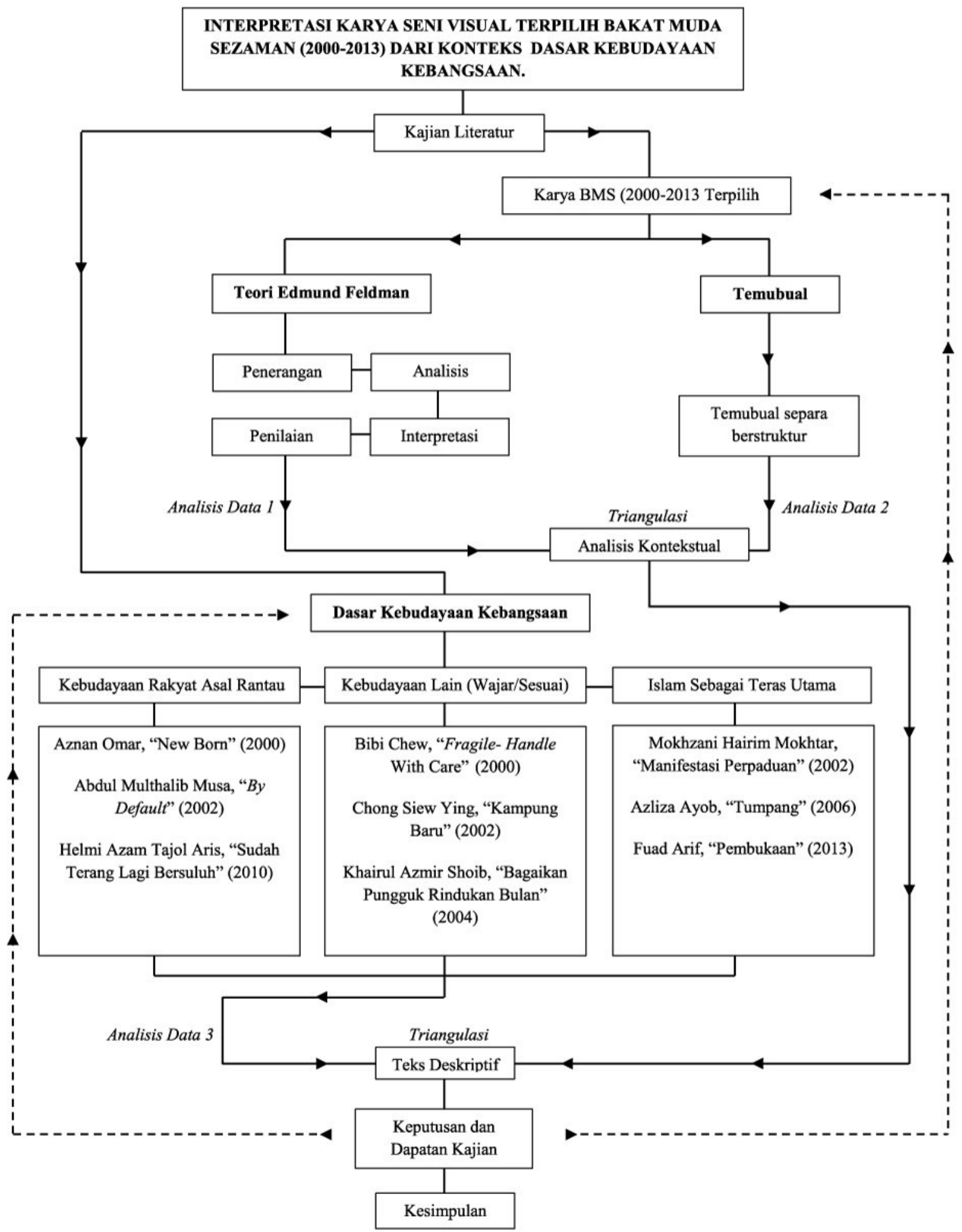

Rajah 1: Rajah menunjukkan kerangka teoritikal keseluruhan kajian. 


\section{DASAR KEBUDAYAAN KEBANGSAAN (1971)}

Kesedaran tentang perlunya sebuah dasar kebudayaan sebenarnya telah wujud sebelum tahun 1971 lagi. Ia dapat dilihat menerusi Kongres Kebudayaan Melayu Pertama Tanah Melayu yang telah diadakan pada 30 Disember 1957 hingga 2 Januari 1958 di Melaka. Kongres ini telah dihadiri oleh 53 buah badan kebudayaan Melayu dari seluruh Semenanjung, Singapura, dan Kalimantan Utara yang menjadi asas kepada teras kebudayaan kebangsaan yang dilaksanakan pada masa ini. Melalui Kongres tersebut, lahirnya ketetapan bahawa "Kebudayaan Melayu boleh dan sesuai dijadikan teras kebudayaan kebangsaan di Tanah Melayu" (Aziz Deraman, 2001). Dr Burhanuddin Al-Helmy di dalam ucapannya pada Kongres Kebudayaan Melayu telah mengatakan:

"Kongres Kebudayaan Melayu yang pertama ini ialah kita mengambil keputusan ketetapan dan bergerak pada membaharui kembali kebudayaan kebangsaan kita di atas asas budaya pusaka kita dalam ketika mencari kerakyatan di negeri pusaka kita ini sedang mula berubah dengan corak baru. Maka dalam perubahan ini bangsa Melayu dan kebudayaan Melayu inilah yang mesti dijadikan asas fardhu rumpun kebudayaan kebangsaan kita yang akan bertunas dan hidup subur dan kembali di antara kebudayaan bangsa-bangsa di dunia kelak."

(Ab. Samad Ahmad (Peny) (1982: 22)

Kongres Kebudayaan Melayu yang pertama ini menunjukkan dengan jelas bahawa terdapat kesedaran yang tinggi di kalangan cendekiawan Melayu akan kepentingan bagi memperkasa dan memperkukuhkan kebudayaan kebangsaan. Hal ini penting bagi memastikan kelangsungan budaya Melayu dan menjadikannya sebagai asas penting kepada kebudayaan kebangsaan. Ketetapan ini bukanlah bersifat perkauman, sebaliknya turut mengambil kira faktor sejarah dan kedudukan orang melayu sebagai masyarakat pribumi bagi rantau ini.

Peristiwa rusuhan kaum pada 13 Mei 1969 yang telah menjadi kemuncak kepada ketegangan kaum di Malaysia dan seterusnya menyebabkan perpecahan yang amat ketara dikalangan rakyat pada ketika itu (Azian Tahir \& Rosiah Md. Noor, 2009). Tragedi ini telah menimbulkan kesedaran baharu tentang perlunya menangani konflik perbezaan kaum yang wujud pada ketika itu. Atas sebab itu, Kongres Kebudayaan Kebangsaan 1971 telah diadakan buat kali pertama oleh kerajaan dan seterusnya memperkenalkan Dasar Kebudayaan Kebangsaan (Azian Tahir \& Rosiah Md. Noor, 2009; N. Ishimatsu, 2011).

Kerajaan Malaysia yang dipimpin parti politik “United Malays National Organisation” (UMNO) telah menetapkan bahawa Dasar Kebudayaan Kebangsaan terbahagi kepada tiga (3) teras:

1. Kebudayaan Kebangsaan Malaysia hendaklah berteraskan kepada kebudayaan rakyat asal rantau ini.

2. Unsur-unsur kebudayaan lain yang sesuai dan wajar boleh diterima menjadi unsur-unsur Kebudayaan Kebangsaan.

3. Islam menjadi unsur penting dalam pembentukan Kebudayaan Kebangsaan itu.

Tiga teras kebudayaan kebangsaan yang dibentuk juga sebenarnya adalah berkisarkan intipati daripada Kongres Kebudayaan Melayu Pertama Tanah Melayu 1957. Perkara ini dinyatakan oleh Anwar Ibrahim (1983):

"Jika kita menyingkap lembaran sejarah, tiga prinsip dasar kebudayaan kebangsaan yang ditetapkan pada tahun 1971 itu adalah pernyataan daripada hakikat sejarah yang secara terus dipertahankan sebagai wasiat suci pembela bangsa dan para pejuang kemerdekaan Negara. Para pejuang kemerdekaan menganjurkan Kongres Kebudayaan Melayu 1957. Kongres ini telah merangkakan dasar kebangsaan bagi Negara merdeka dan berdaulat selepas 31 Ogos 1957 yang merangkumi warganegara baru daripada golongan imigran” (Anwar Ibrahim, 1983) 
Setelah Dasar Kebudayaan Kebangsaan dilaksanakan, ia sering dirujuk sebagai antara dasar penting yang menyumbang kepada kelahiran sebuah negara bangsa. Pelbagai aktiviti kebudayaan yang serasi dengan DKK telah dijalankan oleh kerajaan selain mengwujudkan beberapa akta tertentu yang dapat membantu pihak kerajaan dalam menjamin kelancaran dasar yang diperkenalkan.

\section{DAPATAN KAJIAN}

Penemuan bagi analisis kajian dapat dilihat seperti berikut:

\subsection{Karya 1, 2 dan 3: Unsur kebudayaan kebangsaan berteraskan kebudayaan rakyat asal rantau di dalam karya-karya seni visual artis BMS tahun 2000-2013.}

\begin{tabular}{|c|c|c|}
\hline Karya 1 & $\begin{array}{l}\text { Analisis Be } \\
\text { Feldman (1 }\end{array}$ & $\begin{array}{l}\text { andukan Teori Kritikan Seni } \\
\text { 94) }\end{array}$ \\
\hline 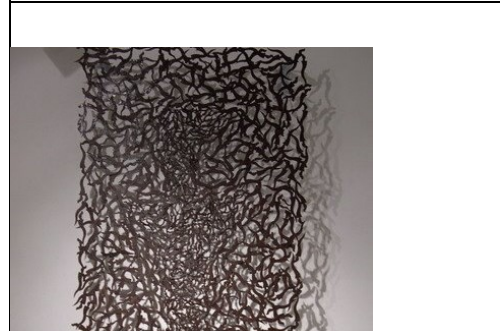 & Deskripsi & $\begin{array}{l}\text { Potongan plat besi } \\
195 \times 85 \mathrm{~cm} \\
\text { Arca dinding (wall sculpture) } \\
\text { Bentuk keris pelbagai saiz } \\
\text { Mengekalkan warna asal plat dalam keadaan } \\
\text { karat besi } \\
\text { Susunan menghasilkan bentuk abstrak }\end{array}$ \\
\hline $\begin{array}{l}\text { "By Default" Abdul Multhalib } \\
\text { Musa (2002) } \\
\text { Media Laser-cut mild plates, } \\
\text { 195 x } 85 \mathrm{~cm} \text {, Bakat Muda } \\
\text { Sezaman 2002 }\end{array}$ & Analisis & $\begin{array}{l}\text { Menggunakan teknik potongan laser bagi } \\
\text { memotong plat besi } \\
\text { Manggunakan pengulangan bentuk (form } \\
\text { repetition). } \\
\text { Karya dipasang terkedahapan dari permukaan } \\
\text { dinding bagi menghasilkan bayang-bayang } \\
\text { rumit (intricate shadow effect) } \\
\text { Penghasilan bentuk keris besar di tengah karya } \\
\text { melalui susunan potongan plat yang } \\
\text { lebih rapat. }\end{array}$ \\
\hline $\begin{array}{l}\text { Katalog Bakat Muda Sezaman } \\
\text { 2002, Balai Seni Visual Negara, } \\
\text { Kuala Lumpur. }\end{array}$ & Interpretasi & $\begin{array}{l}\text { Kritikan terhadap arca-arca awam yang } \\
\text { dihasilkan dengan mengambil rupa bentuk keris } \\
\text { secara menyeluruh. } \\
\text { Satu cadangan dalam menghasilkan karya } \\
\text { berupa keris tradisional dengan } \\
\text { meminjam motif bentuk sahaja. }\end{array}$ \\
\hline & Interpretasi & $\begin{array}{l}\text { Menggunakan 'keris' yang merupakan identiti } \\
\text { masyarakat Malayu sebagai subjek utama karya. } \\
\text { Subjek merupakan ikon dan objek budaya } \\
\text { Melayu }\end{array}$ \\
\hline
\end{tabular}

\begin{tabular}{|l|c|c|c|}
\hline Karya 1 dari konteks DKK & Unsur 1 & Unsur 2 & Unsur 3 \\
\hline $\begin{array}{l}\text { Menggunakan objek budaya } \\
\text { Melayu 'keris' sebagai subjek utama } \\
\text { karya }\end{array}$ & $\square$ & & \\
\hline
\end{tabular}




\begin{tabular}{|c|c|c|}
\hline Karya 2 & \multicolumn{2}{|c|}{ Analisis Berpandukan Teori Kritikan Seni Feldman (1994) } \\
\hline \multirow{4}{*}{$\begin{array}{l}\text { "New Born" Aznan Omar } \\
\text { (2000) } \\
\text { Media Campuran, } 152 \text { x } 95 \text { x } \\
190 \mathrm{~cm} \text {, Bakat Muda Sezaman } \\
2000 . \\
\text { Katalog Bakat Muda Sezaman } \\
\text { 2000, Balai Seni Visual } \\
\text { Negara, Kuala Lumpur. }\end{array}$} & Deskripsi & $\begin{array}{l}\text { Arca bersifat bebas } \\
\text { Bahan industri (besi, aluminium, dan wire rope) } \\
\text { Bahan semulajadi (rotan dari tumbuhan) } \\
\text { Buaian dengan konsep kerusi ayun (rocking } \\
\text { chair) } \\
\text { Dua bahan yang kontra (bahan industri dan } \\
\text { semulajadi) }\end{array}$ \\
\hline & Analisis & $\begin{array}{l}\text { Artis menggambarkan kapsul masa } \\
\text { menggunakan anyaman tiga dimensi (anyaman } \\
\text { raga) } \\
\text { Anyaman kelarai dari tikar mengkuang } \\
\text { menggantikan kanvas buaian. } \\
\text { Plat aluminium dianyam menghasilkan corak } \\
\text { berbentuk dam. }\end{array}$ \\
\hline & Interpretasi & $\begin{array}{l}\text { Buaian sebagai simbol kelahiran kepada era } \\
\text { millenium pada tahun } 2000 . \\
\text { Pertembungan @ asimilasi budaya tempatan } \\
\text { dan luar. } \\
\text { Mengangkat kraf Melayu dalam naratif era } \\
\text { kemodenan. }\end{array}$ \\
\hline & Penilaian & $\begin{array}{l}\text { Menggunakan elemen kraf masyarakat Malayu } \\
\text { sebagai subjek utama karya. } \\
\text { Subjek merupakan ikon dan objek budaya } \\
\text { Melayu }\end{array}$ \\
\hline
\end{tabular}

\begin{tabular}{|l|c|c|c|}
\hline Karya 2 dari konteks DKK & Unsur 1 & Unsur 2 & Unsur 3 \\
\hline $\begin{array}{l}\text { Peminjaman objek kraf Melayu (seni anyaman } \\
\text { tradisional) dalam naratif karya. }\end{array}$ & $\square$ & & \\
& & & \\
\hline
\end{tabular}




\begin{tabular}{|c|c|c|}
\hline Karya 3 & $\begin{array}{l}\text { Analisis Be } \\
\text { Feldman (1 }\end{array}$ & $\begin{array}{l}\text { Indukan Teori Kritikan Seni } \\
\text { 4) }\end{array}$ \\
\hline 3 & Deskripsi & $\begin{array}{l}\text { Sebuah karya instalasi } \\
\text { Media campuran (perspek, cahaya UV dan } \\
\text { perkakasan elektronik). } \\
\text { Subjek lelaki berambut pendek, ikan/makhluk aneh } \\
\text { Imej dilukis pada permukaan perspek } \\
\text { menggunakan cat yang bercahaya di dalam gelap } \\
\text { (glow in the dark) apabila disuluh dengan cahaya } \\
\text { UV. } \\
\text { Imej dilukis dengan dua warna (jingga dan hijau). }\end{array}$ \\
\hline $\begin{array}{l}\text { "Sudah Terang Lagi Bersuluh" } \\
\text { Helmi Azam Tajol Aris (2010) }\end{array}$ & Analisis & $\begin{array}{l}\text { Artis membincangkan teori string dan teori } M \\
\text { berkenaan "parallel universe". } \\
\text { Merujuk kepada satu tempat di dalam dua dimensi } \\
\text { berbeza. } \\
\text { Karya menggabungkan bidang seni dan sains } \\
\text { (interdeciplinarity). }\end{array}$ \\
\hline $\begin{array}{l}\text { Media Campuran, } 213 \text { x } 152 \text { x } \\
20 \mathrm{~cm} \text {, Bakat Muda Sezaman } \\
2010 . \\
\text { Katalog Bakat Muda Sezaman }\end{array}$ & Interpretasi & $\begin{array}{l}\text { Simbolik kepada dunia benar dan palsu melalui dua } \\
\text { imej seakan sama pada dua sisi tetapi mempunyai } \\
\text { rupa berlainan. } \\
\text { Menggunakan elemen wayang kulit (shadow } \\
\text { puppet) dengan dua sisi pandangan } \\
\text { (tok dalang). }\end{array}$ \\
\hline $\begin{array}{l}\text { 2010, Balai Seni Visual } \\
\text { Negara, Kuala Lumpur. }\end{array}$ & Penilaian & $\begin{array}{l}\text { Penggunaan cahaya UV berjaya sebagai simbolik } \\
\text { kepalsuan kerana sesuai dengan fungsi objek. } \\
\text { Meminjam aspek kesenian tradisional Melayu } \\
\text { wayang kulit dalam penyampaian } \\
\text { karya. } \\
\text { Karya dinamakan dengan peribahasa Melayu. }\end{array}$ \\
\hline
\end{tabular}

\begin{tabular}{|l|c|c|c|}
\hline Karya 3 dari konteks DKK & Unsur 1 & Unsur 2 & Unsur 3 \\
\hline $\begin{array}{l}\text { Penggunaan elemen kesenian wayang kulit } \\
\text { dan peribahasa Melayu dalam karya. }\end{array}$ & $\square$ & & \\
\hline
\end{tabular}


Interpretation of 9 Selected Visual Works of Contemporary Young Talent from the Context of the National

\subsection{Karya 4, 5 dan 6: Unsur kebudayaan kebangsaan berteraskan unsur kebudayaan lain yang sesuai dan wajar di dalam karya- karya seni visual artis BMS tahun 2000-2013.}

\begin{tabular}{|c|c|c|c|}
\hline Karya 4 & \multicolumn{3}{|c|}{$\begin{array}{l}\text { Analisis Berpandukan Teori Kritikan Seni } \\
\text { Feldman (1994) }\end{array}$} \\
\hline & Deskripsi & \multicolumn{2}{|c|}{$\begin{array}{l}\text { Sebuah karya instalasi. } \\
275 \times 123.5 \times 191 \mathrm{~cm} . \\
100 \text { botol kaca lutsinar berlainan saiz dan bentuk } \\
\text { diisi dengan tanah dan pasir dari lokasi berbeza. } \\
\text { Botol disusun pada dua rak selari membentuk } \\
\text { laluan. }\end{array}$} \\
\hline "Fragile- Handle With Care" & Analisis & \multicolumn{2}{|c|}{$\begin{array}{l}\text { Penggunaan permukaan plastik putih separa telus } \\
\text { pada belakang rak menghasilkan bayang- bayang } \\
\text { botol. } \\
\text { Laluan pada bahagian tengah rak menggunakan } \\
\text { taburan pasir menjemput penghayat mengambil } \\
\text { bahagian untuk mengalami } \\
\text { secara fizikal. }\end{array}$} \\
\hline $\begin{array}{l}\text { Chew (2000) } \\
\text { Media Campuran, } 275 \text { x } 123.5 \text { x } \\
191 \mathrm{~cm}, \text { Bakat Muda Sezaman } \\
2000 . \\
\text { Katalog Bakat Muda Sezaman } \\
\text { 2000, Balai Seni Visual Negara, }\end{array}$ & Interpretasi & \multicolumn{2}{|c|}{$\begin{array}{l}\text { Perlambangan identiti Malaysia melalui } \\
\text { kepelbagaian jenis tanah yang digunakan. } \\
\text { Tanah sebagai simbolik persamaan sifat pada setiap } \\
\text { masyarakat. } \\
\text { Penggunaan botol sebagai lambang pelaziman } \\
\text { (fizikal, budaya, agama, sosial, dll) yang mencorak } \\
\text { masyarakat } \\
\text { (tanah). }\end{array}$} \\
\hline Kuala Lumpur. & Penilaian & \multicolumn{2}{|c|}{$\begin{array}{l}\text { Penceritaan karya menonjolkan elemen masyarakat } \\
\text { majmuk dalam kerangka "Malaysia" } \\
\text { Pengisian ini bersesuaian dengan masyarakat } \\
\text { majmuk. }\end{array}$} \\
\hline Karya 4 dari konteks DKK & Unsur 1 & Unsur 2 & Unsur 3 \\
\hline $\begin{array}{l}\text { Mesej asimilasi budaya, } \\
\text { simbolik budaya berbeza dalam } \\
\text { sesebuah negara. }\end{array}$ & & $\square$ & \\
\hline
\end{tabular}




\begin{tabular}{|c|c|c|}
\hline Karya 5 & \multicolumn{2}{|c|}{$\begin{array}{l}\text { Analisis Berpandukan Teori Kritikan Seni } \\
\text { Feldman (1994) }\end{array}$} \\
\hline \multirow{4}{*}{$\begin{array}{l}\text { "Kampung Baru” Chong Siew } \\
\text { Ying (2002) } \\
\text { Media Campuran, Pelbagai } \\
\text { Dimensi, Bakat Muda Sezaman } \\
2002 . \\
\text { Katalog Bakat Muda Sezaman } \\
\text { 2002, Balai Seni Visual Negara, } \\
\text { Kuala Lumpur. }\end{array}$} & Deskripsi & $\begin{array}{l}\text { Pelbagai dimensi. } \\
3 \text { meter x } 200 \mathrm{~cm} . \\
\text { Cat minyak pada permukaan kulit binatang (vellum). } \\
\text { Lukisan lapan individu berlainan jantina dan umur. } \\
\text { Lukisan dipapar dalam keadaan melengkung pada } \\
\text { bingkai aluminium. }\end{array}$ \\
\hline & Analisis & $\begin{array}{l}\text { Cat minyak disapu nipis (tidak legap) menyebabkan } \\
\text { cahaya lampu menembusi sapuan cat pada karya. } \\
\text { Karya menceritakan keadaan kampung baru pada } \\
\text { zaman kolonial. } \\
\text { Kampung baru merupakan penempatan baru yang } \\
\text { diwujudkan pada zaman darurat bagi menghalang } \\
\text { pengaruh komunis. }\end{array}$ \\
\hline & Interpretasi & $\begin{array}{l}\text { Susunan karya dalam keadaan melengkung dan } \\
\text { berbingkai menimbulkan rasa sedang memerhatikan } \\
\text { kumpulan masyarakat yang terasing. } \\
\text { Format ini sesuai dengan situasi masyarakat kampung } \\
\text { baru ketika itu yang diperhatikan dan dikawal } \\
\text { oleh tentera British. }\end{array}$ \\
\hline & Penilaian & $\begin{array}{l}\text { Penggunaan cahaya menyebabkan lukisan kelihatan } \\
\text { samar dan menghasilkan warna monokromatik, } \\
\text { memberikan kesan yang baik dalam } \\
\text { penceritaan memori. }\end{array}$ \\
\hline
\end{tabular}

\begin{tabular}{|l|c|c|c|}
\hline Karya 5 dari konteks DKK & Unsur 1 & Unsur 2 & Unsur 3 \\
\hline $\begin{array}{l}\text { "Kampung baru" merupakan budaya sosial yang } \\
\text { wujud kesan dari faktor sejarah. Ia kini menjadi salah } \\
\text { satu elemen unik pengalaman budaya Malaysia. }\end{array}$ & & \\
\hline
\end{tabular}




\begin{tabular}{|c|c|c|}
\hline Karya 6 & \multicolumn{2}{|c|}{$\begin{array}{l}\text { Analisis Berpandukan Teori Kritikan Seni } \\
\text { Feldman (1994) }\end{array}$} \\
\hline \multirow{4}{*}{$\begin{array}{l}\text { "Bagaikan Pungguk Rindukan } \\
\text { Bulan” Khairul Azmir Shoib } \\
\text { (2004) } \\
\text { Media Campuran, Pelbagai } \\
\text { Dimensi, Bakat Muda Sezaman } \\
\text { 2004. } \\
\text { Katalog Bakat Muda Sezaman } \\
\text { 2004, Balai Seni Visual } \\
\text { Negara, Kuala Lumpur. } \\
\end{array}$} & Deskripsi & $\begin{array}{l}\text { Instalasi menggabungkan elemen 2D, 3D dan 4D. } \\
\text { Menggunakan bahan campuran. } \\
3 \times 3 \text { x } 3 \text { meter. } \\
\text { Menampilkan beberapa karakter berupa patung } \\
\text { bersaiz kecil dan animasi video (stop motion). }\end{array}$ \\
\hline & Analisis & $\begin{array}{l}\text { Diberikan judul 'Bagaikan Pungguk Rindukan } \\
\text { Bulan" yang membawa maksud menantikan sesuatu } \\
\text { yang tidak akan tercapai. } \\
\text { Menceritakan tentang Puteri dari Malakut yang } \\
\text { memuja 'bunga majis Arupa' dari } \\
\text { bulan. }\end{array}$ \\
\hline & Interpretasi & $\begin{array}{l}\text { Karya dihasilkan dalam bentuk penceritaan. } \\
\text { Pakaian puteri Malakut diinspirasi daripada patung } \\
\text { Siva Natarajah dan watak Malefica. } \\
\text { Perkataan Malakut bermaksud Imaginasi di dalam } \\
\text { kosmologi Islam. } \\
\text { Di dalam Qaballah (Hebrew), terdapat 'tree of life- } \\
\text { The Sefiroth' yang mempunyai } 10 \text { dahan. } 1 \\
\text { darinya adalah Malkuth. }\end{array}$ \\
\hline & Penilaian & $\begin{array}{l}\text { Karya mempamerkan pengisian kosmologi Islam, } \\
\text { budaya popular barat, unsur Qaballah, Hindu dan } \\
\text { lain- lain lagi. } \\
\text { Menggabungkan pelbagai elemen budaya dalam } \\
\text { karya. }\end{array}$ \\
\hline
\end{tabular}

\begin{tabular}{|c|c|c|c|}
\hline Karya 6 dari konteks DKK & Unsur 1 & Unsur 2 & Unsur 3 \\
\hline $\begin{array}{l}\text { Elemen budaya barat, hindu, hebrew, kosmologi } \\
\text { Islam dan lain-lain memperlihatkan } \\
\text { kepelbagaian unsur budaya dalam sesebuah } \\
\text { karya. }\end{array}$ & & $\square$ & \\
\hline
\end{tabular}




\subsection{Karya 7, 8, dan 9: Unsur kebudayaan kebangsaan berteraskan Islam di dalam karya-karya seni visual artis BMS tahun 2000-2013.}

\begin{tabular}{|c|c|c|}
\hline Karya 7 & \multicolumn{2}{|l|}{$(1994)^{\text {An }}$} \\
\hline & Deskripsi & $\begin{array}{l}\text { Karya arca. } \\
292 \times 40 \text { x } 58 \mathrm{~cm} . \\
\text { Potongan kecil (fragment) kayu yang } \\
\text { dicantumkan menjadi bentuk tali yang bersimpul. } \\
\text { Di letakkan dalam kedudukan menegak. }\end{array}$ \\
\hline & Analisis & $\begin{array}{l}\text { Menggunakan simpulan 'ikatan tindih kasih'. } \\
\text { Bahagian tapak karya dibuat secara berpisah. } \\
\text { Membicarakan impak/kesan tidak bersatu padu } \\
\text { dalam masyarakat. }\end{array}$ \\
\hline "Manifestasi Perpaduan" & Interpretasi & $\begin{array}{l}\text { Perpaduan digambarkan melalui bentuk simpulan } \\
\text { yang kukuh. } \\
\text { Potongan kayu kecil mewakili individu yang } \\
\text { membentuk masyarakat. } \\
\text { Potongan kayu yang dicantumkan } \\
\text { memperlihatkan mesej perpaduan selain rupa } \\
\text { bentuk simpulan tindih } \\
\text { kasih. }\end{array}$ \\
\hline $\begin{array}{l}\text { (2002) } \\
\text { Media Kayu, } 292 \text { x } 40 \text { x } 58 \mathrm{~cm} \\
\text { Katalog Bakat Muda Sezaman } \\
\text { 2002, Balai Seni Visual Negara, } \\
\text { Kuala Lumpur. }\end{array}$ & Penilaian & $\begin{array}{l}\text { Karya menganjurkan nilai positif Islam iaitu } \\
\text { semangat perpaduan. } \\
\text { Karya merupakan refleksi kepada surah Ali Imran } \\
\text { "Berpegang teguhlah dengan tali Allah, dan } \\
\text { janganlah kamu } \\
\text { berpecah belah".. }\end{array}$ \\
\hline
\end{tabular}

\begin{tabular}{|l|c|c|c|}
\hline Karya 7 dari konteks DKK & Unsur 1 & Unsur 2 & Unsur 3 \\
\hline $\begin{array}{l}\text { Karya menyampaikan mesej positif Islam selain } \\
\text { kandungan karya berdasarkan petikan ayat Al- } \\
\text { Quran surah Ali Imran ayat 103. }\end{array}$ & & & $\square$ \\
\hline
\end{tabular}


Interpretation of 9 Selected Visual Works of Contemporary Young Talent from the Context of the National

Interpretasi 9 Karya Seni Visual Terpilih Bakat Muda Sezaman Dari Konteks Teras Dasar Kebudayaan

\begin{tabular}{|c|c|c|}
\hline Karya 8 & $\begin{array}{l}\text { Analisis Be } \\
\text { Feldman (1 }\end{array}$ & andukan Teori Kritikan Seni \\
\hline & Deskripsi & $\begin{array}{l}\text { Sebuah karya instalasi. } \\
\text { Karya dihasilkan menggunakan paper clay yang } \\
\text { membentuk cendawan kecil. } \\
\text { Karya diinstalasi pada beberapa permukaan tiang. }\end{array}$ \\
\hline & Analisis & $\begin{array}{l}\text { Cendawan diwarnakan dengan warna merah yang } \\
\text { terang. } \\
\text { Artis membenarkan penglibatan pengunjung } \\
\text { dengan memetik karya. } \\
\text { Penglibatan pengunjung adalah cerminan } \\
\text { perkongsian dan tolak ansur antara } \\
\text { artis dan penghayat. }\end{array}$ \\
\hline \multirow[t]{2}{*}{$\begin{array}{l}\text { “Tumpang” Azliza Ayob (2006) } \\
\text { Media Kertas Paper Clay, Saiz } \\
\text { Pelbagai. } \\
\text { Katalog Bakat Muda Sezaman 2006, } \\
\text { Balai Seni Visual Negara, Kuala } \\
\text { Lumpur. }\end{array}$} & Interpretasi & $\begin{array}{l}\text { Subjek 'cendawan' menggambarkan sifat lemah } \\
\text { dan tidak berdaya sesuai dengan sifat cendawan } \\
\text { yang menumpang pada tumbuhan lain untuk } \\
\text { kelangsungan hidup. } \\
\text { Sifat lemah ditonjolkan dengan baik melalui } \\
\text { penggunaan medium } \\
\text { rapuh (paper clay). }\end{array}$ \\
\hline & Penilaian & $\begin{array}{l}\text { Karya menganjurkan nilai posotif seperti tolak } \\
\text { ansur, toleransi } \\
\text { dan rendah diri. }\end{array}$ \\
\hline
\end{tabular}

\begin{tabular}{|l|c|c|c|}
\hline Karya 8 dari konteks DKK & Unsur 1 & Unsur 2 & Unsur 3 \\
\hline $\begin{array}{l}\text { Pengisian nilai-nilai Islam seperti zuhud } \\
\text { (rendah diri) dan tsaamuh (tolak ansur) }\end{array}$ & & & \\
yang menjadi intipati & & & \\
ajaran Islam. & & & \\
\hline
\end{tabular}




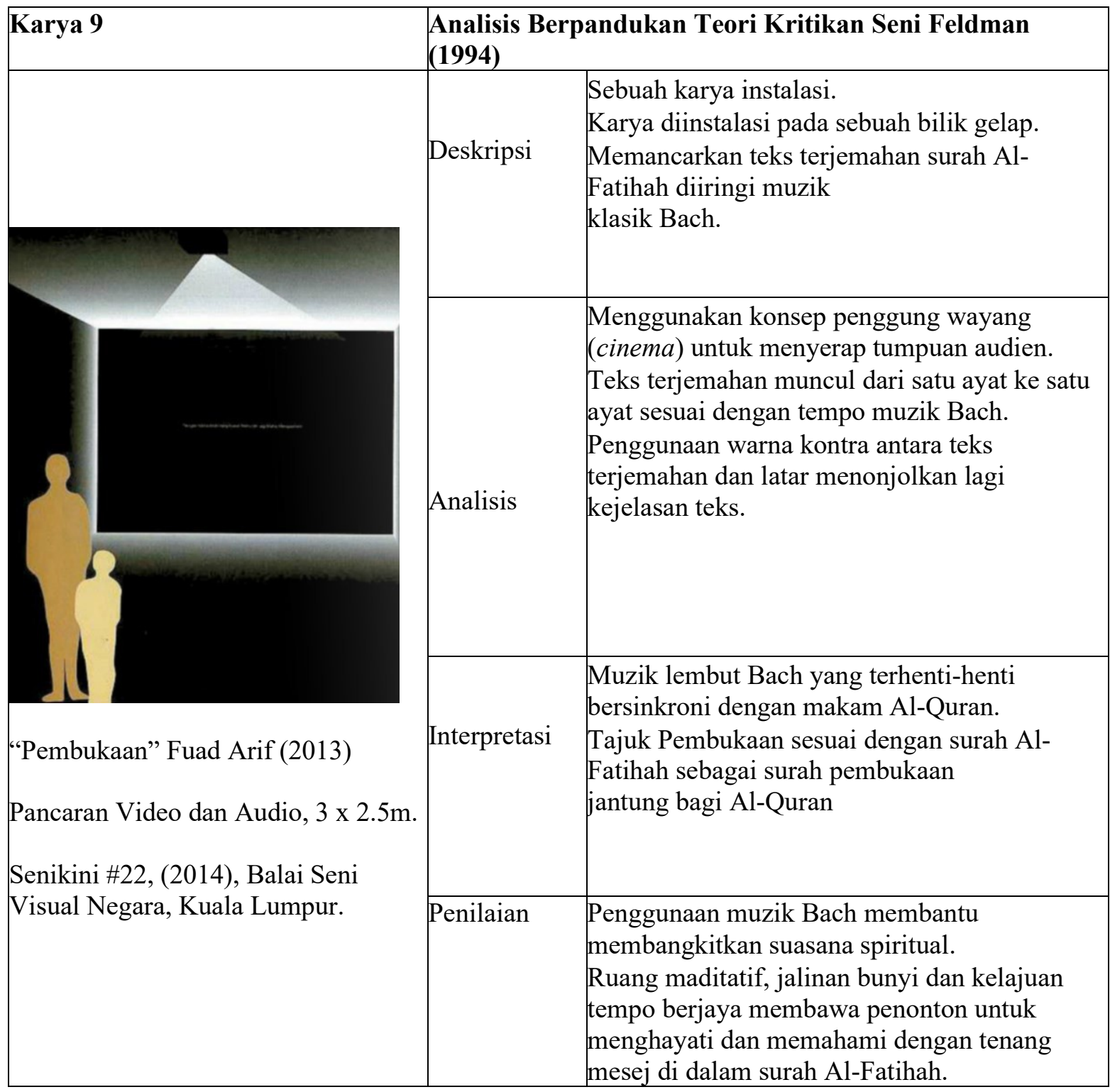

\begin{tabular}{|l|c|c|c|}
\hline Karya 9 dari konteks DKK & Unsur 1 & Unsur 2 & Unsur 3 \\
\hline $\begin{array}{l}\text { Mengangkat intipati kerohanian Islam melalui } \\
\text { pembacaan dan penghayatan } \\
\text { ayat Al-Quran. }\end{array}$ & & & \\
\hline
\end{tabular}

\section{KESIMPULAN}

Berdasarkan daripada hasil kajian ini, dapat disimpulkan bahawa karya- karya artis muda Malaysia jelas masih lagi mengangkat intipati yang terdapat di dalam unsur-unsur DKK. Walaupun DKK telah diwujudkan sejak sekian lama dahulu, kesinambungan artis dalam menghasilkan karya-karya bernafaskan unsur kebudayaan kebangsaan masih ada. Tidak dinafikan, kebanyakkan artis tidak merujuk secara terus berkenaan unsur DKK sebelum mengkasilkan karya tetapi, intipati budaya bersifat kebangsaan sebenarnya telah tertanam di jiwa mereka sama ada sedar ataupun tidak. Melalui temubual yang dijalankan, artis muda BMS mengakui terdapat unsur dan intipati DKK yang terkandung dalam pengisian karya mereka.

Analisis berpandukan teori kritikan seni oleh Feldman E.B (1994) amat membantu dalam memahami 'bentuk' dan 'makna' sesebuah karya seni visual. Pemahaman ini dibantu oleh proses 
kritikan seni yang nyata melalui deskripsi, analisa, interpretasi dan penilaian karya. Pada peringkat deskripsi dan analisa, pengkaji dapat mengetahui dan memahami karya yang dianalisis dari aspek fizikal karya serta pengisian yang ingin disampaikan oleh pengkarya. Peringkat interpretasi dan penilaian pula membantu pengkaji untuk menghubungkan pengisian karya tersebut dengan konteks budaya yang dikaji dan seterusnya menilai kembali keberadaan unsur-unsur budaya kebangsaan di dalam sesebuah karya seni visual.

Melihat kembali kepada karya "By Default" (2002), "New Born" (2000), dan "Sudah Terang Lagi Bersuluh" (2010), ciri-ciri budaya kebangsaan dalam konteks budaya Melayu jelas kelihatan di dalam pengisian karya sama ada dari sudut objek budaya, simbol budaya, motif, serta elemen dan naratif budaya. Karya "By Default" melaui penggunaan simbol keris sebagai subjek utama memperlihatkan keinginan pengkarya untuk mengangkat objek budaya Melayu di dalam seni visualnya. Karya "New Born" oleh Aznan Omar pula menonjolkan seni kraf Melayu yang dijadikan elemen penting di dalam naratif seni visual beliau. Penggunaan anyaman tradisional dalam menyampaikan penceritaan kontemporari menunjukkan kemahuan artis untuk membawa elemen-elemen budaya Melayu dalam aspek perbincangan karya. Begitu juga karya "Sudah Terang Lagi Bersuluh" yang menyelitkan falsafah wayang kulit dalam naratif kontemporari. Berdasarkan analisis berpandukan teori kritikan seni Feldman E.B. (1994), karya-karya ini jelas berada dalam kerangka elemen budaya Melayu dalam konteks budaya kebangsaan.

Karya "Fragile- Handle with Care" (2000), "Kampung Baru" (2002) dan "Bagaikan Pungguk Rindukan Bulan" (2004) pula memperlihatkan keinginan pengkarya yang cuba menerapkan elemen budaya lain di dalam hasil seni visual mereka. "Fragile- Handle With Care" (2000) membawa perlambangan identiti budaya Malaysia melalui pelbagai jenis tanah yang diasimilasi ke dalam botol. Perubahan bentuk mengikut acuan botol itu dilambangkan sebagai pelaziman dari sudut fizikal, budaya, agama mahupun sosial yang akhirnya mencorak sesebuah masyarakat. Karya "Kampung Baru" (2002) juga menceritakan keberadaan budaya baru yang lahir di Malaysia ketika zaman kolonial. Keadaan darurat pada ketika berlakunya konflik zaman komunis membawa kepada pembentukkan kampung baru yang secara tidak langsung melahirkan budaya sosial baru. Berlainan pula dengan karya "Bagaikan Pungguk Rindukan Bulan" (2004), karya ini jelas dipengaruhi aspek barat dari sudut pembinaan karakter subjek, penggayaan karya termasuk konsep dan latar. Pengaruh budaya popular barat ini secara tidak langsung dinilai merangkumi konteks kedua budaya kebangsaan.

Seterusnya tiga lagi karya yang diletakkan di dalam konteks Islam bersesuaian dasar ketiga kebudayaan kebangsaan iaitu "Manifestasi Perpaduan" (2002), "Tumpang" (2006) dan "Pembukaan" (2013). "Manifestasi Perpaduan" (2002) merupakan sebuah arca berbentuk ikatan tali. Pembentukkannya adalah melalui fragmen potongan kayu yang dicantumkan menjadi gambaran simpulan tali gergasi. Namun, interpretasi daripada karya ini jelas berohanikan petikan ayat Al- Quran surah Al-Imran yang menganjurkan ummah supaya bersatu dan tidak berpecah belah. Begitu juga karya tumpang yang menganjurkan konsep yang serupa dengan menyuntik nilai-nilai Islam sebagai naratif karya. Nilai 'tsaamuh' ataupun tolak ansur adalah mesej utama karya yang sangat bertepatan dengan ajaran Islam. Seterusnya karya "Pembukaan" (2013) yang menggunakan surah terjemahan Al- Fatihah sebagai elemen utama karya instalasi. Berlainan dengan dua karya sebelumnya, "Pembukaan" membawa mesej kerohanian yang membawa penghayat memahami dan menghayati setiap bait-bait kalam Allah di dalam surah pembukaan bagi Al-Quran. Ketiga-tiga karya ini setelah dianalisis, dinilai berada dalam konteks Islam yang selari dengan elemen ketiga kebudayaan kebangsaan.

Sampel karya yang didokumentasikan dalam penyelidikan ini membuktikan bagaimana artis-artis muda di dalam pertandingan BMS cuba untuk menyampaikan intipati dan mesej budaya kebangsaan melalui aspek 'Bentuk' dan 'Makna' di dalam karya-karya mereka. Penyelidikan ini telah menunjukkan bahawa artis muda Malaysia melalui platform BMS telah cuba untuk menghasilkan karya seni visual menggunakan pendekatan dan dimensi baru tetapi dalam masa yang sama mengekalkan elemen budaya tempatan yang berkaitan dengan unsur-unsur DKK. Hal ini seterusnya memperlihatkan kepekaan artis muda dalam mengetengahkan nilai dan budaya warisan di dalam seni visual kontemporari. 


\section{RUJUKAN}

Abdul Multhalib Musa. (2008). By Default. Dimuat turun pada 22 Julai 2015 daripada http://www.multhalib.com/2008_05_01_archive.html.

Abdul Samad Ahmad, (Peny). (1982). Kongres Kebudayaan Melayu Pertama (30 Disember 1957- 2 Januari 1958). Majlis Kebudayaan Negeri Melaka, hlm. 22.

Ahmadrashidi Hasan. (2010). Contemporary Islamic painting in Malaysia: 1980 to 2000. Universiti Teknologi MARA.

Azian Tahir \& Rosiah Md. Noor. (2009). Kesedaran Pelukis Moden Malaysia dalam Seni Islam Berlandaskan Dasar Seni Kebangsaan, hlm. 3.

Azian Tahir \& Rosiah Md. Noor. (2010). An Analysis Study on Printmaking Artwork with the National Cultural Identity Theme in Malaysia. i cast. hlm. 7.

Aziz Deraman. (2001). Masyarakat dan Kebudayaan Malaysia. Kuala Lumpur: Dewan Bahasa dan Pustaka.

Bakat Muda Sezaman. (2000). Kuala Lumpur: Balai Seni Lukis Negara.

Bakat Muda Sezaman. (2002). Kuala Lumpur: Balai Seni Lukis Negara.

Bakat Muda Sezaman. (2004). Kuala Lumpur: Balai Seni Lukis Negara.

Bakat Muda Sezaman. (2006). Kuala Lumpur: Balai Seni Lukis Negara.

Bakat Muda Sezaman. (2010). Kuala Lumpur: Balai Seni Lukis Negara.

Bakat Muda Sezaman. (2013). Kuala Lumpur: Balai Seni Lukis Negara.

Faizal Sidek. (2016). Bakat Muda Sezaman: Satu Tinjauan (1974-2010). Dimuat turun pada 2 Ogos 2015 daripada faizalsidik.blogspot.my/2012/07/bakat-muda- sezaman-satu-tinjauan-model.html

Feldman, E. B. (1994). Practical Art Criticism. New Jersey: The University of Georgia.

Lembaga Pembangunan Seni Visual (2013). Bakat Muda Sezaman 2013. Dimuat turun pada 7 Januari 2016 daripada http://e-gov.my/artgallery/pelawat/arkib/pameranaktiviti-terkini/20132/bakat-muda- sezaman-2013/

Lembaga Pembangunan Seni Visual (2016). Bakat Muda Sezaman 2016. Dimuat turun pada 14 November 2016 daripada http://dev.rocketweb.my/lpsvn/ms/bakat-muda-sezaman-2016/

Mulyadi Mahmood. (2012). Taman Nurani: Nafas Keislaman Dalam Seni Kontemporari Malaysia. Kuala Lumpur: Galeri Petronas.

N. Ishimatsu. (2011). Shifting Phasesof the Art Scenes in Malaysia and Thailand: Comparing Colonized and Non-colonized Countries. Institute of Asian Studies, Chulalongkorn University, 2011, hlm. 81.

Noh, L. M. M., Hasan, A., Haron, H., Samian, A. L. (2014). Malay Symbol Expression: An Analysis on Techniques And Media In Malaysian Pictorial Art.

Sarena Abdullah. (2011). Young Contemporaries 2010, Reviewed: sentAp!, April, hlm. 32.

Sarena Abdullah. (2013). Artis-artis Melayu dan Situasi Pascamoden: Pendekatan- pendekatan Bertema Semenjak 1990-an. Reaksi - Strategi Kritikal Baru: Naratif Seni Rupa Jilid 2. Kuala Lumpur: RogueArt.

Temubual bersama Aznan Omar (Pengkarya arca "New Born” Bakat Muda Sezaman 2000) di Restoran Al-Bayan, Seri Iskandar, Perak pada jam 4.45 petang, 3 Febuari 2016.

Temubual bersama Fuad Arif (Pengkarya instalasi "Pembukaan" Bakat Muda Sezaman2013) di Kondominium Puri Aiyu, Shah Alam, Selangor pada jam 3. 22 petang, 6 Febuari 2016.

Temubual bersama Khairul Azmir Shoib (Pengkarya instalasi "Bagaikan Pungguk Rindukan Bulan" Bakat Muda Sezaman 2004) menerusi panggilan telefon, pada jam 2.16 petang, 15 September 2016.

The National Culture Congress. (1971). Kuala Lumpur: Ministry of Sport and Youth, Malaysia.

Young, B. (2000, Julai). Art in malaysia - starting thoughts. Business Time. Di muat turun pada 4 Mac 2015, daripada http://search.proquest.com/docview/266912069?accountid=14645 